\title{
A survey of social workers in Aotearoa New Zealand about their professional use of social media
}

Deb Stanfield, Independent Practitioner, New Zealand

\begin{abstract}
INTRODUCTION: The aim of this article is to report findings from a survey which provides an overall beginning picture of how Aotearoa New Zealand social workers operate in their social media landscape, and an account of their opinions and attitudes about the professional social work use of social media.

METHODS: A self-administered internet survey which sits within the context of a mixed methods research design, gathered broad, shallow, mainly quantitative data (QUAN-qual) from 342 Aotearoa New Zealand social workers about their professional participation in social media. Using Likert-type scales and multiple-choice questions, information was sought about the social work experience (behaviour, opinions/attitudes) of using social media for professional reasons, including motivations, limitations and challenges.
\end{abstract}

FINDINGS: Fewer than half of the respondents reported using social media for professional reasons, and there was reticence amongst participants about the professional value of social media. Concerns about privacy, security and ethical issues were presented as primary limitations to the use of social media by both users and non-users-however, non-users were more likely to be prevented by their employers from using social media and, on average, maintained a more neutral stance regarding their interest in using it.

CONCLUSION: The analysis of findings from this survey offer insight into areas of potential development, leadership and research regarding social worker use of social media in this country.

KEYWORDS: Social work; social media; internet; communications technology

Social media has become almost invisible in the extent to which it has infiltrated society. The term ubiquitous is used by many to describe the phenomenon, which perhaps only just captures the pervasive power of social media, and how quickly it has consumed us (Jenkins, Clinton, Purushotma, Robison, \& Weigel, 2009; Wolf \& Goldkind, 2016). The social media platforms of Facebook and Twitter, although only in existence since the mid-2000s, have penetrated our personal lives, our politics and professional relationships so deeply they have transformed how we relate to each other, and how we gain and share knowledge.

Social workers, alongside their human service colleagues, have been formally interested in the use of computers and information systems in
AOTEAROA

NEW ZEALAND SOCIAL WORK 31(4), 35-47.

CORRESPONDENCE TO Deb Stanfield stanfield.deb@gmail.com 
practice for at least 30 years, when the Human Services in Technology Association (husITa) held its inaugural conference (Ballantyne, Wong, \& Morgan, 2017). Since this time, and particularly since the genesis of social media via the development of Web 2.0 in 2004, social work research and writing about social media has slowly developed internationally, especially in the realm of ethics, and social work education (Kellsey \& Taylor, 2016; Maidment, 2005; Stanfield, 2019; Westwood, 2014; Wretman \& Macy, 2016). The novelty of social media has provided a "wide open" space for social work research, with multiple questions continuing to accumulate about practice relevance, professionalism, technical and ethical competence.

The first reference to Aotearoa New Zealand social work and the internet was published in 2001 by a lone social work academic (O'Donoghue, 2001), who offered a review of international social work websites which, at the time, included networking sites, tips, guides, access to information, resources, discussion forums and sites which marketed educational institutions and agency services. An argument was made for expanding internet use by Aotearoa New Zealand social workers and their professional organisations, suggesting that, in addition to a number of professional benefits, not to do so would "potentially run the future risk of our unique professional identity and bicultural critical reflective practitioner model being threatened again from the dominant discourse of the North Western Hemisphere cultures" (O'Donoghue, 2001, p. 47). There is recognition in this article of the potential practice value of the internet for social workers, and a recommendation for the critical use of technology to avoid its dominance over the centrality of human relationships so important to social work.

A guest blog series on a Aotearoa New Zealand social work research blogsite in 2013 and 2014 served to revive the topic of social media for social workers in this country, inviting social workers to strongly consider the relevance of social media to their profession, citing the high use of social media by New Zealanders generally as inspiration, and offering tips and support to those wishing to use social media professionally (Ballantyne, 2013a, $2013 b$, 2014). This blogger made an anecdotal observation that Aotearoa New Zealand social workers are less visible as professional users of social media compared with their peers from other developed countries. This was apparent despite the fact that New Zealanders generally used social media at a rate equivalent to other countries (Crothers, Smith, Urale, \& Bell, 2015).

A closed Facebook group was started in 2014 for social workers in Aotearoa New Zealand (SWANZ) which became the subject of an exploratory case study, generating insight into what Aotearoa New Zealand social workers value about the professional use of social media, and what problems or issues they encountered in its use (Stanfield, Beddoe, Ballantyne, Lowe, \& Renata, 2017). Findings from this project, and an earlier one which considered the place of professional identity in social work use of social media (Stanfield \& Beddoe, 2016), both aligned with what was being reported in the international literature, namely that social media offers social workers the opportunity to network, gain access to professional knowledge and to participate in debate and activism. Social media also introduces complex challenges around ethics, privacy and other professional issues (Boddy \& Dominelli, 2016; Chan, 2016; McAuliffe \& Nipperess, 2017; Reamer, 2017; Taylor, 2017). It was clear from these small studies that Aotearoa New Zealand social workers faced similar interests and challenges to their colleagues in other western jurisdictions.

The self-administered internet survey reported in this article was administered to social workers in Aotearoa New Zealand in 2014. Its intent was to build on the limited local social work knowledge about how social workers in Aotearoa New Zealand were participating professionally in social media, and to explore opinions about the value of social media to the social work 
profession, and its perceived benefits and barriers. It also sought views about the need for further education or training related to competent and effective use of social media by social workers.

\section{Method}

Survey participants were drawn from the membership of Aotearoa New Zealand Association of Social Workers (ANZASW), a voluntary professional organisation that provides competency assessment and advocacy services to social workers. Approval to survey its membership was granted by the Chief Executive Officer (CEO) of ANZASW, and an email invitation to participate in the research was sent to all members. This invitation included a description of the research, participant information sheet, and a link to the survey landing page. The survey was run for three months and participation was taken as consent. The study received ethical approval from the University of Auckland Human Participants Ethics Committee (UAHPEC).

\section{Survey design}

The self-administered survey was used to seek broad, shallow, mainly quantitative data from social workers in Aotearoa New Zealand about their professional use of social media, and their opinions about the usefulness of social media to the profession. The survey questionnaire, distributed using SurveyMonkey began with a brief definition of social media supported with examples of well-known platforms (for example Facebook, Twitter, LinkedIn, blogs), and using Likert-type scales and multiple-choice questions, sought information about the social work experience (behaviour, opinions, attitudes) of using social media for professional reasons, including motivations, limitations and challenges. The survey was pilottested on two occasions to ensure clarity of language, smooth technical functioning, and to confirm the survey would take approximately five minutes to complete. Table 1 illustrates how participants were moved through the survey:

Table 1. Survey Questions

\begin{tabular}{|c|c|}
\hline \multicolumn{2}{|c|}{ Do you use social media for professional social work reasons? } \\
\hline YES & NO \\
\hline $\begin{array}{l}\text { How frequently do you use social media for professional social work } \\
\text { reasons? (multiple choice) }\end{array}$ & $\begin{array}{l}\text { What prevents you from using social media for professional social } \\
\text { work reasons? (multiple choice and comment) }\end{array}$ \\
\hline $\begin{array}{l}\text { Why do you use social media for professional social work reasons? } \\
\text { (multiple choice and comment) }\end{array}$ & $\begin{array}{l}\text { How satisfied are you with your use of social media for professional } \\
\text { social work reasons? (Likert scale) } \\
5=\text { very satisfied, } 1 \text { = very dissatisfied }\end{array}$ \\
\hline $\begin{array}{l}\text { How important is social media to you in your professional role as a } \\
\text { social worker? (Likert scale) } \\
5 \text { = very important, } 1 \text { = very unimportant }\end{array}$ & $\begin{array}{l}\text { How interested are you in using social media for professional social } \\
\text { work reasons? (Likert scale) } \\
5=\text { very interested, } 1=\text { very disinterested }\end{array}$ \\
\hline \multicolumn{2}{|l|}{$\begin{array}{l}\text { How satisfied are you with your use of social media for professional } \\
\text { reasons? (Likert scale) } \\
5=\text { very satisfied, } 1=\text { very dissatisfied }\end{array}$} \\
\hline $\begin{array}{l}\text { What prevents you from using social media for professional social } \\
\text { work reasons more than you currently do? (multiple choice and } \\
\text { comment) }\end{array}$ & \\
\hline
\end{tabular}

Which social media activity do you engage in as a professional social worker? (multiple choice and comment) 


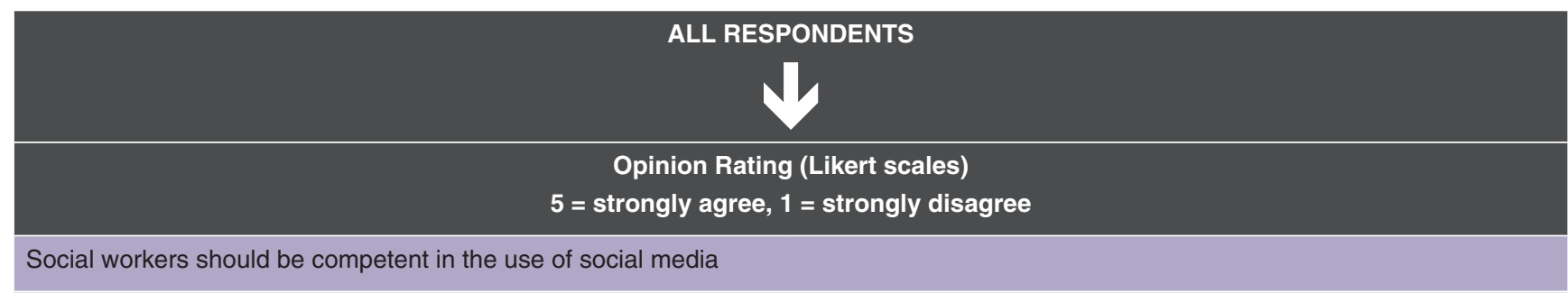

Social workers should make professional use of social media

Social workers should be offered training on how to use social media safely

Social workers should be offered training on the potential professional uses of social media

Please offer your opinion about the usefulness of social media to each of the following professional social work activities:(professional development, research, networking, advocacy, service delivery, info sharing)

$5=$ very useful, $1=$ not useful at all

\section{Do you use social media for personal reasons? (Y N)}

\section{Demographics}

Which age group to you belong to?

Which ethnic group(s) do you belong to?

What is your gender?

Which category represents the number of years you have practised as a social worker?

\section{Further comments}

\section{Participants}

The survey data of 310 social workers were analysed for this research, representing just under $10 \%$ of the membership of ANZASW of which there were 3430 members at the time the survey was distributed (ANZASW, 2013). There were 4029 registered social workers in Aotearoa New Zealand when this survey was run (Social Workers Registration Board (SWRB), 2013); however, as registration was not then mandatory in Aotearoa New Zealand, it was difficult to establish how many people in this country were employed as social workers, a title that the SWRB has only recently succeeded in protecting via a drive for mandatory registration under the Social Workers Registration Act 2003 (SWRB, 2019).

Acknowledging the debate at the time of the survey around the unprotected title of social worker (and therefore its definition), it is fair to say that the 3430 members of ANZASW offered a reasonable representation of 4029 registered social workers practising in Aotearoa New Zealand during the period over which this survey was distributed.

Additionally, comparison of the age and gender demographic information of ANZASW with that of the survey participants shows that distribution of survey participants represents the population of interest. Survey participants could choose from seven age groups, and descriptive statistics suggest that the average age group of the survey respondents was 45 to 54 years $(m=4.08, S D=1.17)$. The average age group of the ANZASW membership was 46 to 55 years $(m=4, S D=1.1)$. The survey was also closely representative in terms of gender, with approximately $83 \%$ being female and $17 \%$ male. These figures reflect the aging demographic and the skewed gender balance of the social work profession 
in Aotearoa at the time of the study. Demographic data about ethnicity were collected from the survey; however, because of the significant differences in how the data were collected, it is difficult to demonstrate statistically how representative the survey sample was in relation to the ANZASW membership.

\section{Survey analysis}

All data were exported from SurveyMonkey into IBM SPSS 24 (2015). Two separate datasets were created for those who specified that they use social media for social work purposes (Dataset A) and those who do not (Dataset B). Data checking and cleaning was carried out separately on each dataset. Final datasets for analysis contained 144 cases (users) and 166 cases (non-users), with a total of 310 participants.

To capture the significance of the data gathered via this survey, statistical analysis included measures of central tendency and frequency distribution. Bivariate analysis explored the relationship between the demographics of the respondents, and their use of social media, by cross-tabulating variables. And comparisons were made between specific sets of data; for example, a comparison between those who use social media and those who do not in relation to their views about its usefulness and importance to the social work profession. Qualitative comments were arranged into themes, and a selection of comments are presented in the findings below, allowing for a more contextual interpretation of the quantitative data (Bryman \& Cramer, 2005; Fink, 2003).

\section{Findings}

\section{Social media use}

As described earlier, of the 310 social workers surveyed, less than half (46.5\%) declared they used social media for professional purposes $(n=144)$. These participants were asked about the frequency of this use, and descriptive statistics for this question suggest that, on average, respondents used social media between once a week and a few times a week ( $m=4.7, S D=1.7)$. Use of social media, therefore, was interpreted as being part of a regular routine with a sustained rather than casual or ad hoc interest in what was happening in their social media worlds. Just over $12 \%$ of respondents used social media every day, and approximately one quarter of respondents used social media once a month or less. Just over half of the social workers who identified as social media users $(n=78)$, used it for professional networking reasons, whereas just over a quarter $(n=40)$ used it in relation to direct work with clients.

(See Table 2 below). Participants were invited to comment on their reasons for using social media, and these answers included using social media to connect with students, to look for educational resources, to connect with or locate missing young people, birth families or adopted people. Social media was also used to communicate with families and agencies, to locate resources for clients, and gather information about current events or issues.

Over half of the survey respondents (53.5\%) declared they did not use social media for professional purposes $(n=166)$. These respondents were asked to indicate their interest in doing so. Descriptive statistics for this question indicate that, on average, nonusers of social media for professional reasons were neither interested nor disinterested in

Table 2. Reasons for Using Social Media

\begin{tabular}{|l|c|c|}
\multicolumn{1}{|c|}{ Reasons } & Frequency & Percent \\
\hline Professional networking & 78 & $55 \%$ \\
\hline Information sharing & 69 & $49 \%$ \\
\hline Research & 66 & $47 \%$ \\
\hline $\begin{array}{l}\text { Professional } \\
\text { development }\end{array}$ & 65 & $46 \%$ \\
\hline Client work & 40 & $28 \%$ \\
\hline Advocacy & 24 & $17 \%$ \\
\hline
\end{tabular}


using it professionally ( $m=3.08, S D=1.22)$. This neutral stance offers some insight into the desire of non-social media users to become engaged; however, it is also useful to consider the cumulative percentage figures to further understand the responses. Approximately one third of respondents were actively disinterested (33.2\%), and almost half of the respondents $(46.3 \%)$ were actively interested; approximately $20 \%$ took a neutral stance in this regard, indicating a level of indifference and/or cautious openness.

Most participants (almost 70\%) were over the age of $45 ; 30 \%$ under the age of 45 , and $8 \%$ under the age of 34 . A non-significant relationship was found between the age of respondents, and the professional use of social media $\left(X^{2}(2.6)=4, p=.63, n s\right)$. The main difference between users and non-users of social media and age group was found in the category containing respondents over the age of 65 , who represent just over $8 \%$ of all survey respondents $(n=26)$. One third of participants over the age of 65 use social media for professional purposes, and although the small sample number deters us from generalising the findings, anecdotal comments from respondents reflect a commonly held belief that older people are less frequent/competent users of social media.

Participants were asked about their personal use of social media to understand the potential relationship between personal and professional use of social media for social workers. The results showed that $91.5 \%(n=130)$ of respondents who described themselves as using social media professionally, used social media personally, and that $68 \%(n=115)$ of those who did not use social professionally, used social media personally. There were a small number of respondents $(n=12)$ who professed to using social media on a professional basis only.

Those who used social media personally constituted nearly $80 \%$ of the survey respondents $(n=245)$. At the time of this survey nine out of 10 New Zealanders used the internet, $81 \%$ thought the internet was an important way to find information, $60 \%$ read blogs, $65 \%$ used social networking sites (Crothers, Gibson, Smith, Bell, \& Miller, 2014, p. 17). Although it is difficult to compare the data from these two sources given the use of language (social media; internet), a rough correlation can be observed between the number of social workers in this study who used social media, and that of the general population of Aotearoa New Zealand.

\section{Barriers to social media use}

The key features of social media identified in the literature thought to hinder or challenge its use generally relate to various types of risk (privacy, reputational, security, ethical), to lack of time or knowledge and to employment-related factors. Survey participants were offered these factors as possible limitations (users of social media) or barriers (non-users of social media) and were prompted to choose one or more answers to the question about what limited or prevented them from using social media professionally (see Table 3).

Concern about privacy dominated the response to this question, indicating that

Table 3. Limiting and Preventive Factors: Users and Non-users of Professional Social Media

\begin{tabular}{|l|c|c|}
\hline \multicolumn{1}{|c|}{ Barriers } & $\begin{array}{c}\text { Users } \\
\boldsymbol{n}=144\end{array}$ & $\begin{array}{c}\text { Non-users } \\
\boldsymbol{n}=166\end{array}$ \\
\hline Privacy risk & $55.6 \%$ & $57.8 \%$ \\
\hline Time constraints & $40.3 \%$ & $30.7 \%$ \\
\hline Security risk & $37.5 \%$ & $38.6 \%$ \\
\hline Ethical issues & $31.9 \%$ & $34.3 \%$ \\
\hline Lack of knowledge & $27.8 \%$ & $21 \%$ \\
\hline Employer says no & $22.9 \%$ & $32 \%$ \\
\hline Reputational risk & $18.1 \%$ & $20 \%$ \\
\hline No employer guidance & $14.6 \%$ & $30 \%$ \\
\hline Lack of internet access & $11.8 \%$ & $7.8 \%$ \\
\hline
\end{tabular}


over half of the social workers responding to this survey were constrained by this perceived or real risk, and the data presented from both users and nonusers of social media were similar in this respect. The same pattern was observed for concerns about security risk, reputational risk and ethical concerns, with both users and non-users putting similar weight on those factors. Comments were made regarding the ethical implications of social media in direct client work, one commenting that they would only use it in situations of limited confidentiality (i.e., safety), and another stating a wish to safeguard client confidentiality (i.e., what they might post on Facebook). One survey participant expressed no faith in being able to manage risks presented by social media while others highlighted risks inherent in social media including concern about ethical boundaries and fear of posted content being misused or misquoted.

Time constraints featured as a significant preventive factor for all participantshowever, it was more of an issue for users $(40.3 \%)$ than for non-users $(30.7 \%)$ - possibly explained by the reality of social media being more apparent to users; therefore, the experience of time consumption was a more obvious constraining factor. There was also a difference between users and non-users in relation to how lack of knowledge about social media acted as a hindrance. A total of $21 \%$ of non-users saw this as a barrier to use, whereas a higher number of users $(27.8 \%)$ cited it as a limitation. Again, this may be a result of users having experienced the complexity of social media, therefore being more cognizant of the knowledge required to use it well:

I would love to use social media more in my work as I work with teenagers and that is their world. I see that my limitation is my lack of knowledge, I have a very supportive working environment where we are all working to enhance our technological knowledge as we see this is crucial in our work.
Furthermore, non-users were more likely to be affected by lack of employer guidance $(30 \%)$ than were users $(14.6 \%)$, and nonusers were more likely to be advised by their employers not to use social media (30\%) than those who used it (22.9\%). Related to this, one participant commented on the desire for professional guidance in social media use: "I would be really interested in thoughts around the possibilities of adding 'professional use of social media' as part of a competency requirement with ANZASW / SWRB." Several comments were made about the organisational barriers to professional social media use: "I only do social work from my place of work, and social media is NOT allowed on work computers." A further comment illuminates the reality of this for some:

In the context of using social media at work, this is a no-no. Access to social media is banned/blocked. I am however linked to ANZASW through Facebook at home and the social action sites and use these to keep up knowledge...learning and development I guess...in my own time however.

The above comment, made by a non-user of social media highlights the grey area between the professional and the personal in the social media space, and the difference between individual and organisational perceptions of the value of social media. It could indicate that social workers who used social media at home to extend and develop themselves as social workers, did not describe it as a professional use because it was not supported by their employer, or used in the workplace. It is very difficult, therefore, to fully understand how social workers differentiate between professional and personal use of social media. The following comment highlights this dilemma further:

I use my personal social media for professional reasons. Networking, advocacy and information sharing. I find it challenging to consider how 
to keep my personal and professional life separate in this context (i.e., My Facebook "friends" who should really be professional contacts).

In addition to grappling with issues related to personal and professional boundaries, participants also identified the lack of relevance to their work as a limiting factor to social media use:

I think there would need to be a clear purpose, so far it has not come up as a need or something that could be appropriate in my role.

Other limitations identified in the comments include lack of faith in the veracity and usefulness of information found on social media.

From the user dataset, a very small number of participants $(n=11,7.5 \%)$ said that nothing prevented them from using social media, indicating how very few participants had an experience of using social media free of limitations or worries. The following comment highlights the enthusiasm with which one participant embraced social media, perhaps illustrating the experience of this minority:

I believe social media use is imperative for social work because there are various movements overseas, e.g., against sexual assault, against male entitlement and misogyny, for indigenous rights, LGBT rights and marriage equality, economic equality, self-care (e.g., mindfulness meditation, yoga), against organisational and corporate oppression, as well as a huge diversity of spiritual communities and training attended by people from all over the world. If NZ social workers are not using social media, we are not part of the worldwide social change movement and the valuable networking that is available to help us to connect clients with resources.

Respondents were prompted to offer comments in response to the question about their interest in using social media. Of the eight comments, all but one expressed uncertainty and/or a desire for more information before engaging in social media use. As representative of these comments, one participant expressed: "social media needs to be a safe and responsible option, but I don't have enough information to decide as I have limited information [as to] what the possibilities are." Two single comments were made to express more extreme opinions; one a belief that social media is "essential for modern practitioners," the other saying they "don't think social media can help."

\section{Opinions about professional social media use}

All survey participants were prompted to answer the same set of questions seeking their opinions about, and attitudes towards, social worker use of social media. These included questions about the potential and value of social media to the social work profession, and about the need for further knowledge and training (see Table 1).

Participants were asked to use a five-point Likert scale of response alternatives between strongly agree (5) and strongly disagree (1) to rate their opinions and attitudes. In order to best understand and compare the data collected from these questions, the mean was calculated for each question and compared between datasets (see Table 4 ).

It is clear from this table that participants essentially offered at least a basic agreement with each statement about professional social media use. Those statements generating a stronger level of agreement were related to training about the safety of social media, and its potential for use. Participants were, on average, less enthusiastic about the idea that social workers should use social media, however, they agreed that competence was important, either to the profession generally, or as an expectation of all social workers.

The comment offered by the participant below helps to understand the difference in the level of agreement between opinions 
Table 4. Opinion and Attitude Towards Professional Social Media Use: Comparison of Mean and SD $(n=310)$

\begin{tabular}{|c|c|c|}
\hline Survey Questions & Mean (M) & Standard Deviation (SD) \\
\hline Competent social media use is important to the profession & 3.25 & 1.218 \\
\hline $\begin{array}{l}\text { Social workers should be trained in how to use social } \\
\text { media safely }\end{array}$ & 3.77 & 1.120 \\
\hline $\begin{array}{l}\text { Social workers should make professional use of social } \\
\text { media }\end{array}$ & 2.92 & 1.129 \\
\hline $\begin{array}{l}\text { Social workers should be competent in their use of social } \\
\text { media }\end{array}$ & 3.27 & 1.164 \\
\hline $\begin{array}{l}\text { Social workers should be trained in the potential use of } \\
\text { social media }\end{array}$ & 3.79 & 1.101 \\
\hline
\end{tabular}

related to the need for social workers to use social media, and the need for training.

I think if people are using social media they need to be well trained in it but I do not see social media as necessary. I acknowledge that I am one of the few!

Regardless of this participant's perception of being in a minority regarding their position, it suggests an "inevitability" of social media use, and a corresponding requirement for it to be used professionally. Overall, these data indicate a general desire of social workers for training to be offered in the professional use of social media and there is little difference noted between means and standard deviations across categories.

The use and non-use of social media by the respondents to this survey resulted in data that essentially divided the survey respondents in half. Gaining insight into the attitudes and thinking behind these decisions was one of the goals of this survey and it was useful to compare the opinions between users and non-users about the professional importance of social media. This was achieved by cross-tabulating the data collected from users and non-users of social media. Results found, for example, that non-users of social media disagreed more than users with the statement that competent use of social media is important to the social work profession, and a significant relationship was found in this regard $\left(X^{2}(4)=39.78, p<.01\right)$. The survey also sought opinion about the importance of training for social workers in the potential uses of social media and cross-tabulating data from this question found that users of social media were more likely to value the importance of training than non-users $\left(X^{2}(4)=21.7, p<.01\right)$. Although these were expected results, they were important questions to put to the data. Given the number of limitations to professional social media use cited in the literature, and the degree to which all survey participants experienced these limitations, it could not be assumed that opinions about professional importance are linked to actual social media use.

\section{Discussion}

The social workers in Aotearoa New Zealand who responded to this survey were almost equally split as to their use or non-use of social media for professional purposes. This describes a generally ambivalent, possibly divided profession in 2014. Although some respondents saw social media as a "way forward," expressing the need for social workers to "become social media competent to survive," others expressed uncertainty about social media or, further, a dismissal of its use by social workers. They cited lack of employer support and ethical concerns as key limitations and perceived a risk to face-to-face relationships as expressed by this respondent:

There are so many ethical dilemmas that surround social media. It is not 
safe and could have the tendency to eliminate face to face contact. This reduces the human factor.

Extreme positions are common in the face of novelty, and polarised opinion is a feature of current social media analysis (Fuchs, 2017). Social media at once offers the strength of accessibility but with questions about quality, the usefulness as a practice tool but with questions about ethics. Polarity of opinion also leads to a level of indecisiveness and uncertainty which may explain why the survey participants, when asked for their opinions about social media, offered an overwhelmingly neutral response with very little standard deviation. Overall, the impression left by the voices of participants in this study is that of overall uncertainty, and sense of being in the midst of change, as illustrated by the following final comment:

I work for CYF [statutory child protection agency], my answers may change radically as CYF are due to roll out iPads \& iPhones, \& to update policies \& access to social media.

The preceding comment is worthy of exploration five years on, leading as it does to a natural curiosity about whether answers to this survey would be radically different today. Other indicators, such as the increased general use of social media in Aotearoa New Zealand (International Telecommunications Union, 2017) and the growing quantity of social work writing and research (Stanfield, 2019) go some way to support an argument that professional social media use amongst social workers has increased since this time. Further research is required to confirm this hypothesis. However, regardless of this being the case, questions continue to exist about the experience of social workers "on the ground." For example, referring again to the above participant comment: how are social media devices like iPads actually being used, how have policies and ethical guidelines been updated to support their use, and how has organisational access to social media for social workers changed? While these new questions are being investigated, questions arising from the findings of the survey reported in this article continue to be unanswered and worthy of addressing.

For example, findings suggest social workers were seeking guidance and leadership regarding professional use of social media. Since the survey was run, the SWRB, the regulatory authority for social workers in Aotearoa New Zealand, has included a limited guide to social media use in its revised Code of Conduct (SWRB, 2016). The ANZASW is this country's voluntary professional body which provides membership competency assessment, advocacy services, and online professional development opportunities for members (ANZASW, 2013). The association amended its practice standards in 2014, requiring that members are "able to evidence safe and ethical and competent use of digital and internet technology, in both personal and professional circumstances (ANZASW, 2014, p. 8). This standard is not accompanied by a social media guide, however. The recognition by SWRB and ANZASW that internet technology and social media use is relevant to practice is helpful-however, social workers in this survey asked for robust guidance and training in its application, thus offering a clear, ongoing mandate to our professional organisation and regulatory body.

This mandate extends to social work employers. Considering the complexity of professional identity in a social media space, it is hardly surprising that more than half of the survey respondents felt constrained by concern about privacy, and the same anxiety appears to exist within organisations, as evidenced by the number of respondents deterred from using social media at work by their employers. This type of policy is used to manage organisational reputation and risk and highlights the role organisations play in influencing boundaries between personal and private use of social media. In addition, use of social media in direct practice appears to be where the greatest uncertainty lies for social 
workers and social service organisations. Of those survey respondents using social media professionally, only $28 \%$ disclosed using it in direct practice and all survey respondents on average agreed that it was useful in this aspect of their work - but with less conviction than for any other professional use of social media. This reality confirms the need for leadership and support from social work employers which, for consistency and best practice, would be done in collaboration with the ethical and professional guidance of ANZASW and SWRB.

There was overall agreement from those surveyed that training is important, both in the competent use of social media, and in its potential professional applications. This suggests that both practising social workers and social work students would benefit from such training and education. In addition, nearly half the social workers who used social media responded in the survey that they did so for professional development. Roughly the same percentage said they used social media for research purposes, information sharing and professional networking-all arguably professional development activities. The average opinion of survey respondents about the usefulness of social media for these activities was between useful and very useful. These findings suggest that social workers were open to using social media for training and professional development purposes, offering a clear message to their employers, qualifying and professional bodies that opportunities in this regard were important and relevant to social workers.

\section{Conclusion}

Social media is complex, and its use in the professional realm is contested across a range of human services (Susskind \& Susskind, 2015). Its complexity for social work is influenced by the unique identity and mandate of the profession, as well as the cultural and national context in which it is practised (boyd, 2011; Stanfield \& Beddoe, 2016; Turner, 2016). For example, Aotearoa New Zealand social work is imbedded in a bicultural context, guided by the principles of Te Tiriti o Waitangi, thus creating a unique practice environment and cultural identity which strongly influences the practice of social work in this country. Alongside this, there is a growing collection of Aotearoa New Zealand writing about social media from an indigenous perspective. There is exploration, for example, into how the identity of Aotearoa New Zealand Māori is affected by use of social networking sites, the role social media plays in the development of cultural identity (Muhamad-Brandner, 2010), and about how rangatahi (adolescent) Māori use social media (O'Carroll, 2013a). A further study by the same author found that using social media to facilitate whānau connections contributed to overall whānau well-being and enhanced ability to engage in kaupapa whanaungatanga (translated directly to mean connectedness around a common purpose) (O'Carroll, 2013b). An additional contribution of note relates to the concept of e-whanaungatanga (translated directly to mean connectedness via the internet), and the role of social media in Māori political participation (Waitoa, Scheyvens, \& Warren, 2015).

These research examples go some way to highlight the need for advancement in our understanding of the many environments within which social media (and the internet) are situated, how this influences our experience of engaging with social media, and the implications of this engagement. It is argued that social work has an inherent responsibility to advance this knowledge. The advantages of the global nature of the internet and social media are many, but the disadvantages related to the power of this reality are significant, and inherent in this are many risks including the subjugation of the needs of local and vulnerable populations. The study reported in this article offers broad findings about how social workers in this corner of the world use and view social media, and general insight into decision making behind this; however, deeper qualitative exploration is required to understand more fully the many factors that influence these behaviours and attitudes. 
Social service agencies, professional and regulatory bodies in Aotearoa New Zealand require this deep understanding so as to develop policy and support packages unique to this country, to the nature of social work service delivery and to the people it serves. Methodology that supports this exploration may yield findings useful to those exploring similar questions in other parts of the world, and a collaborative effort in this regard would serve to critically challenge the impact of social media on society and the power it wields.

\section{Acknowledgment}

The author gratefully acknowledges the practical guidance for data preparation received from Dr Matthew Courtney, Research Fellow, Data Analysis and Research Unit, School of Learning, Development and Professional Practice, University of Auckland

\section{References}

Aotearoa New Zealand Association of Social Workers. (2013). Annual report 2012/2013. Retrieved from http://anzasw.nz/wp-content/uploads/2012-2013-AnnualReportv2.pdf

Aotearoa New Zealand Association of Social Workers. (2014). ANZASW practice standards. Retrieved from http://anzasw.nz/wp-content/uploads/Practice-StandardPublication-Full-Nov-14.pdf

Ballantyne, N. (2013a, December 3). Reflections on social workers \& social media in Aotearoa: Part 1 [Web log post]. Retrieved from http://socialworkresearchnz. wordpress.com/2013/12/03/reflections-on-socialworkers-social-media-in-aotearoa-part-1/

Ballantyne, N. (2013b, December 13). Reflections on social workers and social media in Aotearoa: Part 2 [Web log post]. Retrieved from https://socialworkresearchnz. wordpress.com/2013/12/13/reflections-on-socialworkers-social-media-in-aotearoa-part-2/

Ballantyne, N. (2014, June 26). Reflections on social work and social media: Part 3 [Web log post]. Retrieved from https://socialworkresearchnz.wordpress.com/2014/06/26/ reflections-on-social-workers-and-social-media-inaotearoa-part-3/

Ballantyne, N., Wong, Y.-C., \& Morgan, G. (2017). Human services and the fourth industrial revolution: From husITa 1987 to husITa 2016. Journal of Technology in Human Services, 35(1), 1-7. doi:10.1080/15228835.2017.1277900

Boddy, J., \& Dominelli, L. (2016). Social media and social work: The challenges of a new ethical space. Australian Social Work, 70(2), 172-184. doi:10.1080/031240 7X.2016.1224907 boyd, d. (2011). Social networking sites as networked publics: Affordances, dynamics, and implications. In Z. Papacharissi (Ed.), A networked self: Identity, community, and culture on social network sites (pp. 39-58). New York, NY: Routledge.

Bryman, A., \& Cramer, D. (2005). Quantitative data analysis with SPSS 12 and 13: A guide for social scientists. London, UK: Routledge.

Chan, C. (2016). A scoping review of social media use in social work practice. Journal of Evidence-Informed Social Work, 13(3), 263-276. doi:10.1080/23761407.20 15.1052908

Crothers, C., Gibson, A., Smith, P., Bell, A., \& Miller, M. (2014). World internet project New Zealand: Internet trends in New Zealand 2007-2013. Auckland, New Zealand: Institute of Culture Discourse and Communications, Auckland University of Technology. Retrieved from https://icdc.aut.ac.nz/ data/assets/ pdf_file/0003/73443/ONLINE-WIPNZ2007_20137_70702a.pdf

Crothers, C., Smith, P., Urale, P., \& Bell, A. (2015). World internet project New Zealand: The internet in New Zealand 2015. Auckland, New Zealand: Institute of Culture, Discourse \& Communication, Auckland University of Technology. Retrieved from https://workresearch.aut.ac.nz/_data/assets/pdf_ file/0003/71328/WIPNZ-Report-060515.pdf

Fink, A. (2003). Data management. In A. Fink (Ed.), How to manage, analyze and interpret survey data (2nd ed., pp. 1-25). Thousand Oaks, CA: SAGE Publications.

Fuchs, C. (2017). Social media: A critical introduction (2nd ed.). London, UK: Sage.

International Telecommunication Union. (2017). Measuring the information society report (Vol. 1). Geneva, Switzerland. ISBN 978-92-61-24521-4 (Electronic version). Retrieved from https://www.itu.int/en/ITU-D/ Statistics/Documents/publications/misr2017/MISR2017_ Volume1.pdf.

Jenkins, H., Clinton, K., Purushotma, R., Robison, A., \& Weigel, M. (2009). Confronting the challenges of participatory culture: Media education for the 21st century. Occasional paper (Vol. 1, pp. 1-59). Boston, MA: MIT/MacArthur Foundation. Retrieved from http://fall2010compositions.pbworks.com/f/JENKINS_ WHITE_PAPER.pdf

Kellsey, D., \& Taylor, A. (2016). The learning wheel: A model of digital pedagogy. Hertfordshire, UK: Critical Publishing.

Maidment, J. (2005). Teaching social work online: Dilemmas and debates. Social Work Education, 24(2), 185-195. doi:10.1080/0261547052000333126

McAuliffe, D., \& Nipperess, S. (2017). e-Professionalism and the ethical use of technology in social work. Australian Social Work, 70(2), 131-134. doi:10.1080/031240 7X.2016.1221790

Muhamad-Brandner, C. (2010). Exploring the cyber-rohe: Māori identity and the internet (Unpublished doctoral dissertation). University of Auckland, New Zealand. Retrieved from https://researchspace.auckland.ac.nz/ handle/2292/6382)

O'Carroll, A. (2013a). An analysis of how rangitahi Māori use social network sites. MAI Journal, 2(1). 
O'Carroll, A. (2013b). Virtual whanaungatanga: Māori utilizing social networking sites to attain and maintain relationships. AlterNative: An International Journal of Indigenous Peoples, 9(3), 230-245. doi:10.1177/117718011300900304

O'Donoghue, K. (2001). Surfing the World Wide Web and social work. Social Work Review, 13(2), 43-48.

Reamer, F. G. (2017). Evolving ethical standards in the digital age. Australian Social Work, 70(2), 148-159. doi: 10.1080/0312407X.2016.1146314

Social Workers Registration Board (SWRB). (2013). Annual report 2012-2013. Wellington, New Zealand. Retrieved from http://swrb.govt.nz/about-us/news-and-publications/ publications/

Social Workers Registration Board (SWRB). (2016). Code of conduct. Wellington, New Zealand. Retrieved from http://swrb.govt.nz/concerns-and-information/codeof-conduct/

Social Workers Registration Board (SWRB). (2019). SWRB welcomes mandatory registration. Wellington, New Zealand. Retrieved from https://swrb.govt.nz/swrbwelcomes-mandatory-registration/

Stanfield, D., \& Beddoe, L. (2016). Social work and social media in Aotearoa New Zealand: Educating social workers across shifting boundaries of social work identity. Social Work Education, 35(3), 284-296. doi:10.1080/02615479.2016.1154663

Stanfield, D., Beddoe, L., Ballantyne, N., Lowe, S., \& Renata, N. (2017). Critical conversations: Social workers' perceptions of the use of a closed Facebook group as a participatory professional space. Aotearoa New Zealand Social Work, 29(3), 42-54.

Stanfield, D. (2019). The professional use of social media by social workers in Aotearoa New Zealand. (Unpublished doctoral thesis). The University of Auckland, New Zealand. Retrieved from http://hdl.handle.net/2292/45171

Susskind, R., \& Susskind, D. (2015). The future of the professions: How technology will transform the work of human experts. Oxford, UK: Open University Press.

Taylor, A. (2017). Social work and digitalisation: Bridging the knowledge gaps. Social Work Education. doi:10.1080/02 615479.2017.1361924

Turner, D. (2016). "Only connect": Unifying the social in socia work and social media. Journal of Social Work Practice, 30(3), 313-327. doi:10.1080/02650533.2016.1215977

Waitoa, J., Scheyvens, R., \& Warren, T. R. (2015). E-Whanaungatanga. AlterNative: An International Journal of Indigenous Peoples, 11(1), 45-58.

Westwood, J. (Ed.). (2014). Social media in social work education. Northwich, UK: Critical Publishing.

Wretman, C. J., \& Macy, R. J. (2016). Technology in social work education: A systematic review. Journal of Social Work Education, 52(4), 409-421. doi:10.1080/10437797.2016.1198293

Wolf, L., \& Goldkind, L. (2016). Digital native meet friendly visitor: A Flexner-inspired call to digital action. Journal of Social Work Education, 52(sup1), S99-S109. doi:10.1080/ 10437797.2016.1174643 